\title{
Reduced Tolerance and Asymmetrical Crosstolerance to Effects of the Indole Quinuclidinone Analog PNR-4-20, a G Protein-Biased Cannabinoid 1 Receptor Agonist in Mice: Comparisons with $\Delta^{9}$-Tetrahydrocannabinol and JWH-018
}

\author{
Benjamin M. Ford, Christian V. Cabanlong, Sherrica Tai, Lirit N. Franks, \\ Narsimha R. Penthala, Peter A. Crooks, Paul L. Prather, and William E. Fantegrossi \\ Department of Pharmacology and Toxicology, College of Medicine (B.M.F., C.V.C., S.T., L.N.F., P.L.P., W.E.F.), and Department \\ of Pharmaceutical Sciences, College of Pharmacy (N.R.P., P.A.C.), University of Arkansas for Medical Sciences, Little Rock, \\ Arkansas
}

Received August 15, 2018; accepted February 11, 2019

\begin{abstract}
Most cannabinoid 1 receptor $\left(\mathrm{CB}_{1} \mathrm{R}\right)$ agonists will signal through both $G$ protein-dependent and -independent pathways in an unbiased manner. Recruitment of $\beta$-arrestin 2 desensitizes and internalizes receptors, producing tolerance that limits therapeutic utility of cannabinoids for chronic conditions. We developed the indole quinuclidinone (IQD) analog (Z)-2-((1-(4-fluorobenzyl)$1 \mathrm{H}$-indol-3-yl)methylene)quinuclidin-3-one (PNR-4-20) as a novel $\mathrm{G}$ protein-biased agonist at $\mathrm{CB}_{1} \mathrm{Rs}$, and the present studies determine if repeated administration of PNR-4-20 produces lesser tolerance to in vivo effects compared with unbiased $\mathrm{CB}_{1} \mathrm{R}$ agonists $\Delta^{9}$-tetrahydrocannabinol $\left(\Delta^{9}-\mathrm{THC}\right)$ and 1-pentyl-3-(1naphthoyl)indole (JWH-018). Adult male National Institutes of Health Swiss mice were administered comparable doses of PNR-4-20 (100 mg/kg), $\Delta^{9}$-THC (30 mg/kg), or JWH-018 (3 mg/kg) once per day for five consecutive days to determine tolerance development to hypothermic, antinociceptive, and cataleptic
\end{abstract}

effects. Persistence of tolerance was then determined after a drug abstinence period. We found that unbiased $\mathrm{CB}_{1} \mathrm{R}$ agonists $\Delta^{9}$-THC and JWH-018 produced similar tolerance to these effects, but lesser tolerance was observed with PNR-4-20 for hypothermic and cataleptic effects. Tolerance to the effects of PNR-4-20 completely recovered after drug abstinence, while residual tolerance was always observed with unbiased $\mathrm{CB}_{1} \mathrm{R}$ agonists. Repeated treatment with PNR-4-20 and $\Delta^{9}-\mathrm{THC}$ produced asymmetric crosstolerance to hypothermic effects. Importantly, binding studies suggest PNR-4-20 produced significantly less downregulation of $\mathrm{CB}_{1} \mathrm{Rs}$ relative to $\Delta^{9}-\mathrm{THC}$ in hypothalamus and thalamus of chronically treated mice. These studies suggest that the $\mathrm{G}$ protein-biased $\mathrm{CB}_{1} \mathrm{R}$ agonist PNR-4-20 produces significantly less tolerance than unbiased cannabinoid agonists, and that the IQD analogs should be investigated further as a novel molecular scaffold for development of new therapeutics.

\section{Introduction}

Investigation of cannabinoid 1 receptors $\left(\mathrm{CB}_{1} \mathrm{Rs}\right)$ and cannabinoid 2 receptors $\left(\mathrm{CB}_{2} \mathrm{Rs}\right)$ has identified numerous ligands with therapeutic potential (Eisenstein, 2015). Cannabinoids such as

This work was supported, in part, by the National Institutes of Health National Institute on Drug Abuse [Grants DA039143 and DA022981], the National Institutes of Health National Institute on General Medical Sciences [IDeA Program Award GM110702], the University of Arkansas for Medical Sciences Translational Research Institute [RR029884], and an Arkansas Research Alliance Scholars Award to P.A.C.

None of the funding sources participated in the study design; the collection, analysis, and interpretation of data; the writing of the report; and the decision to submit the article for publication.

The studies described in this report were submitted in partial fulfillment of a doctoral dissertation to B.M.F.: Ford BM (2017) Characterization of novel molecular scaffolds for cannabinoid receptor ligands: implications for drug development. Doctoral dissertation, University of Arkansas for Medical Sciences, Little Rock, AR.

https://doi.org/10.1124/jpet.118.252965.
$\Delta^{9}$-tetrahydrocannabinol $\left(\Delta^{9}\right.$-THC) have been reported to alleviate cachexia (Cressey, 2015; Reuter and Martin, 2016), chronic pain (Berlach et al., 2006; Lynch and Ware, 2015), anorexia (Verty et al., 2011), and Dravet syndrome (Devinsky et al., 2017; Rosenberg et al., 2017). Numerous states and municipalities within the United States have endorsed the medical use of cannabis, and many laboratories have demonstrated the therapeutic potential of both phytocannabinoids and synthetic cannabinoids (Price et al., 2005; Horswill et al., 2007; Piscitelli et al., 2012; Madadi et al., 2013); however, few such ligands have undergone clinical trials or achieved Food and Drug Administration approval as medications. Currently, two $\Delta^{9}$-THC analogs, dronabinol and nabilone, are indicated for chemotherapy-induced nausea and vomiting but are not highly used treatments in most clinical settings (Muramatsu et al., 2013; Volkow et al., 2014; Pergolizzi et al., 2017). As observed in both clinical studies and incidences of recreational

ABBREVIATIONS: AUC, area under the curve; $\mathrm{CB}_{1} \mathrm{R}$, cannabinoid receptor type $1 ; \mathrm{CB}_{2} \mathrm{R}$, cannabinoid receptor type 2; $\mathrm{CP} 55,940$, 2-[(1R,2R,5R)-5hydroxy-2-(3-hydroxypropyl)cyclohexyl]-5-(2-methyl-2-octanyl)phenol; $\mathrm{E}_{\max }$, maximum effect; IQD, Indole quinuclidinone; JWH-018, 1pentyl-3-(1-naphthoyl)indole; $\Delta^{9}$-THC, $\Delta^{9}$-tetrahydrocannabinol; THC, tetrahydrocannabinol; $t_{\max }$, time to reach the lowest temperature; WIN 55,212-2, (+)-\{(3R)-2,3-dihydro-5-methyl-3-(4-morpholinylmethyl)pyrrolo[1,2,3-de]-1,4-benzoxazin-6-yl\}-(1-naphthalenyl)-methanone. 
abuse, $\mathrm{CB}_{1} \mathrm{R}$ agonists such as $\Delta^{9}$-THC produce a psychotomimetic "high" following acute use, and can produce adverse effects such as tolerance, dependence, and withdrawal following chronic use (Ware et al., 2008; Weinstein and Gorelick, 2011; Cooper et al., 2013; Maida and Daeninck, 2016). Overall, development of cannabinoid ligands devoid of these adverse effects will likely be essential for the widespread acceptability of cannabimimetics as mainstream therapeutics.

In this regard, the biologic effects of cannabinoid ligands are transduced through intracellular signaling mechanisms initiated by binding to $\mathrm{CB}_{1} \mathrm{Rs}$ and $\mathrm{CB}_{2} \mathrm{Rs}$ (Matsuda et al., 1990; Howlett et al., 2002). Interestingly, $\mathrm{CB}_{1} \mathrm{Rs}$ and $\mathrm{CB}_{2} \mathrm{Rs}$ both bind a structurally diverse range of cannabinoid ligands with varying efficacies, including endogenously produced eicosanoids (e.g., anandamide and 2-archidinoylglycerol), plant-derived phytocannabinoids (e.g., $\Delta^{9}$-THC), and synthetic cannabinoids [e.g., 2-[(1R,2R,5R)-5-hydroxy-2-(3-hydroxypropyl) cyclohexyl]-5-(2-methyl-2-octanyl)phenol (CP 55,940); (+)-\{(3R)2,3-dihydro-5-methyl-3-(4-morpholinylmethyl)pyrrolo[1,2,3de]-1,4-benzoxazin-6-yl\}-(1-naphthalenyl)-methanone (WIN 55-212-2); and 1-pentyl-3-(1-naphthoyl)indole (JWH-018)] (Pertwee, 1997, 2006). When unbiased agonist ligands bind these receptors, a convergence of several signaling processes, both $\mathrm{G}$ protein-dependent and -independent, are initiated. For $\mathrm{CB}_{1} \mathrm{Rs}_{\mathrm{s}}, \mathrm{G}$ protein-independent signaling has been shown to hinder therapeutically relevant $G$ protein signaling via $\beta$-arrestin 2-mediated desensitization and downregulation of the receptor (Raehal and Bohn, 2014). $\beta$-Arrestin 2 knockout mice acutely treated with $\Delta^{9}$-THC showed enhanced hypothermia and antinociception, as well as reduced tolerance development following chronic administration (Nguyen et al., 2012; Raehal and Bohn, 2014); however, because traditional cannabinoid agonists function as unbiased ligands and cannot preferentially activate $\mathrm{G}$ protein-dependent signaling without recruiting $\beta$-arrestin 2 , adverse effects such as dependence, tolerance, and withdrawal will always be expected to occur following chronic exposure to traditional $\mathrm{CB}_{1} \mathrm{R}$ agonists. Development of $\mathrm{G}$ protein-biased $\mathrm{CB}_{1} \mathrm{R}$ agonists might minimize or avoid these adverse effects, thus improving the therapeutic profile of cannabinoid-based medications.

We have recently reported a novel class of indole quinuclidinone (IQD) analogs that represent an entirely new structural family of cannabinoid ligands, perhaps implying novel drug-receptor interactions (Ford et al., 2017). Unlike traditional $\mathrm{CB}_{1} \mathrm{R}$ ligands, our lead compound (Z)-2-((1-(4-fluorobenzyl)1H-indol-3-yl)methylene)quinuclidin-3-one (PNR-4-20) functioned as a high-efficacy agonist for modulation of $\mathrm{G}$ protein-dependent signaling via $\mathrm{CB}_{1} \mathrm{Rs}_{\mathrm{s}}$ in Chinese hamster ovary cells, while recruiting little $\beta$-arrestin 2 and producing significantly less receptor desensitization and downregulation following chronic exposure. The G protein-biased agonism exhibited by PNR-4-20 at $\mathrm{CB}_{1} \mathrm{R}$ thus represents a novel mechanism in cannabinoid pharmacology. In vivo studies confirmed that PNR-4-20 elicited dose-dependent $\mathrm{CB}_{1} \mathrm{R}$ mediated effects in the cannabinoid tetrad in the mouse; however, consistent with the $G$ protein bias demonstrated in vitro, mice treated with PNR-4-20 once per day for five consecutive days exhibited reduced tolerance to hypothermic effects upon drug readministration after a 7-day abstinence period compared with animals treated identically with either $\Delta^{9}$-THC or JWH-018 (Ford et al., 2017). In those studies, in vivo effects were assessed at only a single timepoint after each drug administration, perhaps obscuring important differences among drugs. Similarly, assessment of rectal temperature might have been confounded by stress effects, which may have been differentially modulated by the three cannabinoids tested. Nevertheless, additional studies also demonstrated dramatically reduced signs of rimonabantprecipitated withdrawal in mice chronically treated with PNR-4-20 compared with mice chronically treated with JWH-018 (Ford et al., 2017). Because Food and Drug Administration-approved cannabinoids such as dronabinol and nabilone are used for chronic conditions like persistent nausea and wasting syndromes associated with cancer and AIDS (Guzmán, 2003), in this study we were interested in further determining if chronic administration of PNR-4-20 would produce either reduced or less persistent tolerance to cannabinoid-induced effects when compared with unbiased $\mathrm{CB}_{1} \mathrm{R}$ agonists. Using implantable radiotelemetry probes, we sought to noninvasively assess drug-elicited changes in core temperature over time in the much less stressful environment of the home cage. For the first time, we also assessed crosstolerance to hypothermic effects between PNR-4-20 and $\Delta^{9}$-THC; characterized tolerance to antinociceptive and cataleptic effects of PNR-4-20, JWH-018, and $\Delta^{9}$-THC; and investigated $\mathrm{CB}_{1} \mathrm{R}$ expression in therapeutically relevant brain areas drawn from mice chronically administered PNR-4-20 or $\Delta^{9}$-THC. Understanding the effects of chronic PNR-4-20 on different physiologic endpoints in mice could further aid in the development of improved therapeutics based on this novel molecular scaffold.

\section{Materials and Methods}

Drugs. The IQD analog PNR-4-20 was synthesized in our laboratories, as previously described (Franks et al., 2014). WIN 55,212-2 and CP 55,940 were purchased from Tocris Bioscience (Bristol, United Kingdom). JWH-018 and $\Delta^{9}$-THC were obtained from the NIDA Drug Supply Program (Bethesda, MD). Rimonabant was synthesized in the laboratory of Thomas E. Prisinzano, Ph.D., at the Department of Medicinal Chemistry, University of Kentucky School of Pharmacy (Lexington, KY). [ $\left.{ }^{3} \mathrm{H}\right] \mathrm{CP} 55,940(175 \mathrm{Ci} / \mathrm{mmol})$ was obtained from PerkinElmer (Waltham, MA). All other reagents used were purchased from Thermofisher Scientific (Pittsburgh, PA). For in vitro assays, all cannabinoids were dissolved in $100 \%$ DMSO to $10 \mathrm{mM}$ stock concentrations. For in vivo assays, all cannabinoids were dissolved in a vehicle containing ethanol, Tween 80 , and saline at a ratio of 1:1: 18. All injections were administered intraperitoneally at a constant volume of $0.01 \mathrm{cc} / \mathrm{g}$.

Animals. All studies used adult male National Institutes of Health Swiss mice and were conducted in accordance with the Guide for Care and Use of Laboratory Animals, 8th edition (https://grants.nih.gov/ grants/olaw/guide-for-the-care-and-use-of-laboratory-animals.pdf) as adopted and proclaimed by the National Institutes of Health. The University of Arkansas for Medical Sciences Institutional Animal Care and Use Committee approved all animal use protocols. All efforts were taken to minimize animal suffering and reduce the number of animals used. Mice were obtained from Harlan Laboratories, Inc. (Indianapolis, IN), arriving at 9 weeks of age and weighing between 20 and $25 \mathrm{~g}$. All subjects were housed three animals per cage $\left(15.24 \times 25.40 \times 12.70 \mathrm{~cm}^{3}\right)$ in a temperature-controlled room in an Association for Assessment and Accreditation of Laboratory Animal Care-accredited animal facility. Room conditions were maintained at $22 \pm 2{ }^{\circ} \mathrm{C}$ and $45 \%-50 \%$ humidity, with lights set to a 12-hour light/dark cycle. Animals were fed laboratory diet rodent chow (Laboratory Rodent Diet No. 5001; PMI Feeds, St. Louis, MO) ad libitum until immediately before testing. 
Drug Administration. All test conditions used groups of either five or six mice, which were randomly assigned to experimental groups, and all mice were drug-naive prior to the present studies. Based on our previous work (Ford et al., 2017), we studied doses of $\Delta^{9}$-THC (30 mg/kg), JW-018 (3 mg/kg), and PNR-4-20 (100 mg/kg) producing comparable hypothermic effects in all of the in vivo assays discussed in detail subsequently.

Biotelemetry of Core Temperature. Surgical preparation and real-time data collection using biotelemetry probes were conducted as previously described (Gannon et al., 2016). Briefly, the abdominal area of each mouse was shaved and sterilized with iodine swabs following anesthetization with inhaled isoflurane. A rostral-caudal cut approximately $1.5 \mathrm{~cm}$ in length was made with sterile skin scissors, providing access to the intraperitoneal cavity. A cylindrical glass-encapsulated radiotelemetry probe (model ER-4000 E-Mitter; Mini Mitter Co., Inc., Bend, OR) was then inserted, and the incision was closed using 5-0 absorbable suture material. Surgeries were carried out 14 days before initiation of each experiment, allowing time for incisions to heal. After surgery, all implanted mice were individually housed in $15.24 \times$ $25.40 \times 12.70 \mathrm{~cm}$ cages for the duration of all telemetry experiments. Implanted transmitters produced temperature-modulated signals that were sent to a receiver (model ER-4000 Receiver; Mini Mitter Co., Inc.) underneath each cage. Every 5 minutes, the computer collected data updates from the probes for core temperature readings (in degrees Celsius). After approximately 60 minutes of baseline data collection, mice were injected with either vehicle or test compound and returned to the telemetry stage for 24 hours of data collection. For rimonabant antagonism assays, $10 \mathrm{mg} / \mathrm{kg}$ rimonabant was administered 15 minutes prior to cannabinoid exposure. After rimonabant injection, mice were placed back into their home cages during this 15-minute period.

Warm Water Tail Withdrawal. To measure tail withdrawal latency, each mouse was securely immobilized in the investigator's hand while the tail was allowed to hang freely. The distal $5 \mathrm{~cm}$ portion of the tail was dipped into a StableTemp (Cole-Parmer, Vernon Hills, IL) heat-controlled water bath maintained at $50^{\circ} \mathrm{C}$, and a maximal latency cutoff time of 15 seconds was used to minimize tissue damage. Mice could remove their tails from the water at any point and the amount of time the tails remained in the water was measured with a stopwatch. Baseline tail withdrawal latencies ranged from 3 to 5 seconds. To ensure that tail withdrawal was due specifically to the nociceptive stimulus of the $50^{\circ} \mathrm{C}$ water and not a learned response over the course of multiple dips, a non-nociceptive control test with $45^{\circ} \mathrm{C}$ water was performed for each animal midway through the experimental session. On experimental test days, mice were injected with vehicle, $3 \mathrm{mg} / \mathrm{kg} \mathrm{JW}-018,30 \mathrm{mg} / \mathrm{kg} \Delta^{9}$-THC, or $100 \mathrm{mg} / \mathrm{kg}$ PNR-4-20. As previously determined, different pretreatment times were used for each drug to ensure maximal antinociceptive effects at the time of testing, such that $3 \mathrm{mg} / \mathrm{kg} J W-018$ was administered 60 minutes prior to testing, $30 \mathrm{mg} / \mathrm{kg} \Delta^{9}$-THC was administered 45 minutes before testing, and PNR-4-20 was administered 35 minutes prior to testing. Because mice were injected every 24 hours for 5 days, a group of vehicle control mice were also tested to ensure that the effects observed across successive drug groups were due to drug-induced tolerance and not to confounding factors such as stress or hyperalgesia. To reduce stress-induced effects on analgesia, mice were acclimated to the procedure 1 week before drugs were administered. The habituation procedure was performed as previously described, except injections were excluded.

Catalepsy. Catalepsy was measured using the horizontal bar test, which employed a cylindrical steel bar $(0.5 \mathrm{~cm}$ in diameter $)$ that was supported $4.0 \mathrm{~cm}$ above a covered platform. The mice studied in the warm water tail withdrawal assay were also used in this assay without any additional drug dosing. To begin each trial, mice were placed into a species-atypical position with hindlimbs on the platform and forelimbs on the horizontal bar. Upon placement on the catalepsy bar, a timer was started and counted until the mouse removed both paws from the bar. The maximum time allowed on the bar was
20 seconds; because we often observed habituation to the catalepsy procedure with repeated testing, animals were only tested for catalepsy on days 1,5 , and 12 .

Crosstolerance between PNR-4-20 and $\Delta^{\mathbf{9}}$-THC. Experiments investigating crosstolerance to hypothermic effects were conducted as previously described (Tai et al., 2015). Briefly, two treatment groups of animals had biotelemetry probes surgically implanted as described in Materials and Methods. Drug treatments for one group involved administration of $100 \mathrm{mg} / \mathrm{kg}$ PNR-4-20 every 24 hours for 4 days followed by an injection of $30 \mathrm{mg} / \mathrm{kg} \Delta^{9}$-THC on test day 5 , while the other group received injections of $30 \mathrm{mg} / \mathrm{kg} \Delta^{9}$-THC every 24 hours for 4 days followed by an injection of $100 \mathrm{mg} / \mathrm{kg}$ PNR-4-20 on test day 5 .

Tissue Collection and Membrane Preparation. Three separate groups of mice were administered vehicle, $30 \mathrm{mg} / \mathrm{kg} \Delta^{9}$-THC, or $100 \mathrm{mg} / \mathrm{kg}$ PNR-4-20 every 24 hours for 5 days. Twenty-four hours following the last injection, mice were euthanized via cervical dislocation and decapitation. Whole brains were immediately removed and hypothalamus and thalamus regions were hand dissected out on ice, then snap-frozen in liquid nitrogen and stored at $-80^{\circ} \mathrm{C}$. To prepare regional homogenates, dissected hypothalamus and thalamus were homogenized separately with 10 complete strokes utilizing a $40 \mathrm{ml}$ Dounce glass homogenizer in ice-cold buffer containing $50 \mathrm{mM}$ HEPES (pH 7.4), $3 \mathrm{mM} \mathrm{MgCl}_{2}$, and $1 \mathrm{mM}$ EDTA. Homogenized samples were then centrifuged at $40,000 \mathrm{~g}$ for 10 minutes at $4^{\circ} \mathrm{C}$. Supernatants were removed and pellets were resuspended in ice-cold buffer, homogenized again, and centrifuged similarly two additional times. After the last centrifugation step, supernatants were removed and the remaining hypothalamus and thalamus membranes were resuspended in ice-cold $50 \mathrm{mM}$ HEPES ( $\mathrm{pH}$ 7.4) to achieve an approximate protein concentration of $2 \mathrm{mg} / \mathrm{ml}$. Membrane homogenates were divided into respective aliquots and stored at $-80^{\circ} \mathrm{C}$ for future use. A $100 \mu \mathrm{l}$ aliquot of each membrane preparation was removed prior to freezing and the protein concentration was determined using a BCA Protein Assay (Thermo Fisher Scientific, Waltham, MA).

Homologous Receptor Binding. Homologous receptor binding was performed as previously described (Brents et al., 2012). Briefly, respective reaction mixtures contained increasing concentrations of the nonradioactive competing ligand CP 55,940 in a $50 \mathrm{mM}$ Tris- $\mathrm{HCl}$ buffer ( $\mathrm{pH} 7.4$ ) with $0.1 \%$ bovine serum albumin, $5 \mathrm{mM} \mathrm{MgCl}_{2}, 0.5 \mathrm{nM}$ $\left[{ }^{3} \mathrm{H}\right] \mathrm{CP} 55,940$, and either $20 \mu \mathrm{g}$ of saline (or drug-treated hypothalamus membrane homogenates) or $50 \mu \mathrm{g}$ of treated vehicle (or drugtreated thalamus membrane homogenates). The total volume of the incubation mixture was $1 \mathrm{ml}$. All reactions were mixed and allowed to reach equilibrium binding via incubation at $37^{\circ} \mathrm{C}$ for 15 minutes. Nonspecific binding was defined as the amount of radioligand binding remaining in the presence of a $1 \mu \mathrm{M}$ concentration of the nonradioactive, high-affinity, nonselective cannabinoid receptor agonist WIN 55,212-2. Binding was terminated via rapid vacuum filtration through glass fiber filters (Brandel, Gaithersburg, MD), followed by four $5 \mathrm{ml}$ washes of ice-cold $50 \mathrm{mM}$ Tris- $\mathrm{HCl}(\mathrm{pH}$ 7.4) buffer containing $0.1 \%$ bovine serum albumin. Then, $4 \mathrm{ml}$ of scintiverse scintillation fluid (Fisher Scientific) was added to the respective filters and radioactivity was quantified 24 hours later utilizing liquid scintillation spectrophotometry.

Statistical Analyses. All data are presented as group mean \pm S.E.M. Points without error bars indicate that the variance is contained within the data point. For tolerance and crosstolerance studies, one-way repeated measures ANOVAs with Tukey's honest significant difference post-hoc test compared the mean lowest temperature achieved after each injection [vehicle or each of five daily drug administrations; represented as the time to reach the lowest temperature $\left.\left(t_{\max }\right)\right]$, as well as the lowest average temperature achieved in each drug group [represented as the maximum effect $\left.\left(E_{\max }\right)\right]$. The area under the curve (AUC) between the average baseline temperature of vehicle-treated animals and real-time core temperature readings of drug-treated animals during a 300-minute exposure window were calculated by subtracting the AUC beneath respective 


\section{TABLE 1}

Parameters of $\Delta^{9}$-THC- and PNR-4-20-elicited hypothermia

The $E_{\max }$ values are presented as the mean \pm S.E.M. of the lowest temperatures for each animal on each respective day and compound. The $t_{\max }$ values indicate time (in minutes) when maximal hypothermic effects were observed for each respective day and compound. The AUC is given for each respective compound. Asterisks indicate $E_{\max }$ values that are significantly different from vehicle-treated animals. $N$ denotes number of subjects. Dashes indicate vehicle values could not be determined because effects were not observed.

\begin{tabular}{|c|c|c|c|c|c|c|c|c|}
\hline \multirow{2}{*}{ Day } & \multicolumn{4}{|c|}{$30 \mathrm{mg} / \mathrm{kg} \Delta^{9}-\mathrm{THC}$} & \multicolumn{4}{|c|}{100 mg/kg PNR-4-20 } \\
\hline & $E_{\max }$ & $t_{\max }$ & AUC & $N$ & $E_{\max }$ & $t_{\max }$ & AUC & $N$ \\
\hline & ${ }^{\circ} \mathrm{C}$ & $\min$ & & & ${ }^{\circ} \mathrm{C}$ & $\min$ & & \\
\hline Vehicle & $37.44 \pm 0.31$ & - & - & 5 & $37.21 \pm 0.33$ & - & - & 5 \\
\hline 1 & & 50 & 947 & 5 & ;* & 35 & 536 & 5 \\
\hline 2 & $7 \pm 0$ & 30 & 523 & 5 & $2 \pm$ & 25 & 355 & 5 \\
\hline 3 & $36.03 \pm 0$. & 55 & 185 & 5 & $36.29 \pm 0$ & 25 & 170 & 5 \\
\hline 4 & $0+0$ & 280 & 59 & 5 & $35.56 \pm 0$ & 25 & 241 & \\
\hline & $36.14 \pm 0$. & 70 & 141 & 5 & $35.34 \pm 0$ & 25 & 216 & 5 \\
\hline Retest $^{a}$ & $35.72 \pm 0.40^{*}$ & 80 & 445 & 5 & $33.33 \pm 0.54^{*}$ & 35 & 438 & 5 \\
\hline
\end{tabular}

${ }^{a}$ The retest was done after a 14-day drug abstinence period.

core temperature regressions from the AUC of the average baseline temperature. In Tables 1 and 2, $E_{\max }$ represents the lowest temperature achieved during each drug exposure, while $t_{\max }$ shows the time (in minutes) at which the lowest temperature occurred. These parameters were compared by one-way repeated measures ANOVA, followed by Dunnet's post-hoc test to compare all drug conditions to the vehicle controls. For analgesia and catalepsy tests, a two-way repeated measures ANOVA, with day and drug as independent factors, followed by Tukey's honest significant difference post-hoc test assessed differences among groups. Each in vitro data point presented in all figures is represented as the mean \pm S.E.M. from a minimum of four individual experiments. Three-parameter nonlinear regression for one-site homologous binding was used to determine the affinity $\left(K_{\mathrm{d}}\right)$ of $\left[{ }^{3} \mathrm{H}\right] \mathrm{CP} 55,940$ and $\mathrm{CB}_{1} \mathrm{R}$ density $\left(B_{\max }\right)$ expression in crude whole mouse brain homogenates. One-way ANOVA's and Tukey's honest significant difference post-hoc test were used to compare $K_{\mathrm{d}}$ and $B_{\max }$ values for respective compounds in thalamus and hypothalamus brain regions. All in vivo and ex vivo statistical calculations were performed using GraphPad Prism version 7.03 (GraphPad Software Inc., Le Jolla, CA), and statistical significance was always judged at $P<0.05$

\section{Results}

Mice Chronically Treated with $100 \mathrm{mg} / \mathrm{kg}$ PNR-4-20 Exhibited Less Tolerance to Cannabinoid-Induced Hypothermic Effects when Compared with $30 \mathrm{mg} / \mathrm{kg}$ $\Delta^{\mathbf{9}}$-THC. Core temperatures following administration of vehicle, $30 \mathrm{mg} / \mathrm{kg} \Delta^{9}$-THC (Fig. 1A), or $100 \mathrm{mg} / \mathrm{kg}$ PNR-4-20 (Fig. 1D) were significantly different among groups $[F(2,14)=$ 47.88 for $\Delta^{9}$-THC; $F(2,12)=13.06$ for PNR-4-20; $P<0.05$ for both comparisons]. Indeed, both $\Delta^{9}$-THC $(q=12.01 ; P<0.05)$ and PNR-4-20 $(q=6.233 ; P<0.05)$ elicited hypothermic effects that were significantly different from those observed following vehicle administration. Importantly, the hypothermic effects of both $\Delta^{9}$-THC and PNR-4-20 were completely blocked by prior administration of $10 \mathrm{mg} / \mathrm{kg}$ of the selective $\mathrm{CB}_{1} \mathrm{R}$ antagonist/inverse agonist, rimonabant. Statistical testing revealed that core temperatures following rimonabant $+\Delta^{9}$ THC $(q=0.787 ; P>0.05)$ or rimonabant + PNR-4-20 $(q=0.052$; $P>0.05)$ did not differ from those observed following vehicle injection. Importantly, the AUC for hypothermic effects (calculated for each individual animal making up the mean data presented in Fig. 1, B and E) were not significantly different for $\Delta^{9}$-THC and PNR-4-20 when either drug was administered to naive mice $(q=2.078 ; P>0.05)$.

When mice were injected with either $\Delta^{9}$-THC or PNR-4-20 for five consecutive days, changes in $E_{\max }, t_{\max }$, and AUC were apparent across days (Table 1 ). $\Delta^{9}$-THC produced a significant drop in core body temperature $[F(6,24)=10.684 ; P<$ 0.05] compared with vehicle administration, but this effect depended on the number of times the drug was administered (Fig. 1C). Following the initial injection, the core temperature dropped $\sim 4^{\circ} \mathrm{C}$, and since mice were repeatedly treated every 24 hours for the remaining 4 days, development of tolerance was apparent as indicated by a progressive blunting of $\Delta^{9}$ THC-induced hypothermia. Indeed, only the first $(q=10.005$; $P<0.05)$ and second $(q=5.879 ; P<0.05)$ daily $\Delta^{9}$-THC injections elicited hypothermic effects that were different from those observed following vehicle injection, while the third ( $q=$ 7.358; $P<0.05)$, fourth $(q=7.521 ; P<0.05)$, and fifth $(q=$ 7.843; $P<0.05$ ) daily injections elicited effects that were significantly different from those observed after the first $\Delta^{9}$ THC injection. No other between-day comparisons were significant during this 5-day period of repeated drug administration. When retested with $\Delta^{9}$-THC after a 14-day drug abstinence period, persistent tolerance was noted, since the hypothermic effects observed were different from both vehicle treatment $(q=4.972 ; P<0.05)$ and the initial $\Delta^{9}$-THC injection $(q=5.033 ; P<0.05)$ (Fig. 1C; Table 1). Similarly, PNR-4-20 also produced a significant drop in core body temperature $[F(6,24)=10.364 ; P<0.05]$ compared with vehicle administration, but this effect also depended on the number of times the drug was administered (Fig. 1F).

\section{TABLE 2}

Parameters of crosstolerance between PNR-4-20 and $\Delta^{9}$-THC

The $E_{\max }$ values are presented as the mean \pm S.E.M. of maximal hypothermic temperatures produced for each respective day and compound. The $t_{\max }$ values indicate time (in minutes) when maximal hypothermic effects were observed for each respective day and compound. The AUC is given for each respective compound. Asterisks indicate $E_{\text {max }}$ values that are significantly different from vehicle-treated animals. $N$ denotes number of subjects. Dashes indicate vehicle values could not be determined because effects were not observed.

\begin{tabular}{|c|c|c|c|c|c|c|c|c|c|}
\hline \multicolumn{5}{|c|}{ 4-day 100 mg/kg PNR-4-20 } & \multicolumn{5}{|c|}{ 4-day $30 \mathrm{mg} / \mathrm{kg} \Delta^{9}$-THC } \\
\hline Day & $E_{\max }$ & $t_{\max }$ & AUC & $N$ & Day & $E_{\max }$ & $t_{\max }$ & AUC & $N$ \\
\hline & ${ }^{\circ} \mathrm{C}$ & $\min$ & & & & ${ }^{\circ} \mathrm{C}$ & $\min$ & & \\
\hline Vehicle & $37.29 \pm 0.33$ & - & - & 5 & Vehicle & $37.29 \pm 0.31$ & - & - & 5 \\
\hline 1 & $32.09 \pm 0.19^{*}$ & 30 & 567 & 5 & 1 & $31.59 \pm 0.17^{*}$ & 60 & 973 & 5 \\
\hline 2 & $34.50 \pm 0.95^{*}$ & 30 & 490 & 5 & 2 & $33.67 \pm 0.32^{*}$ & 55 & 557 & 5 \\
\hline 3 & $34.72 \pm 0.57 *$ & 25 & 534 & 5 & 3 & $34.95 \pm 0.28$ & 50 & 362 & 5 \\
\hline & $34.26 \pm 0.24^{*}$ & 35 & 492 & 5 & 4 & $34.97 \pm 0.13$ & 160 & 380 & 5 \\
\hline$\Delta^{9}$-THC & $33.98 \pm 0.23^{*}$ & 125 & 865 & 5 & PNR-4-20 & $34.62 \pm 0.32$ & 30 & 311 & 5 \\
\hline
\end{tabular}



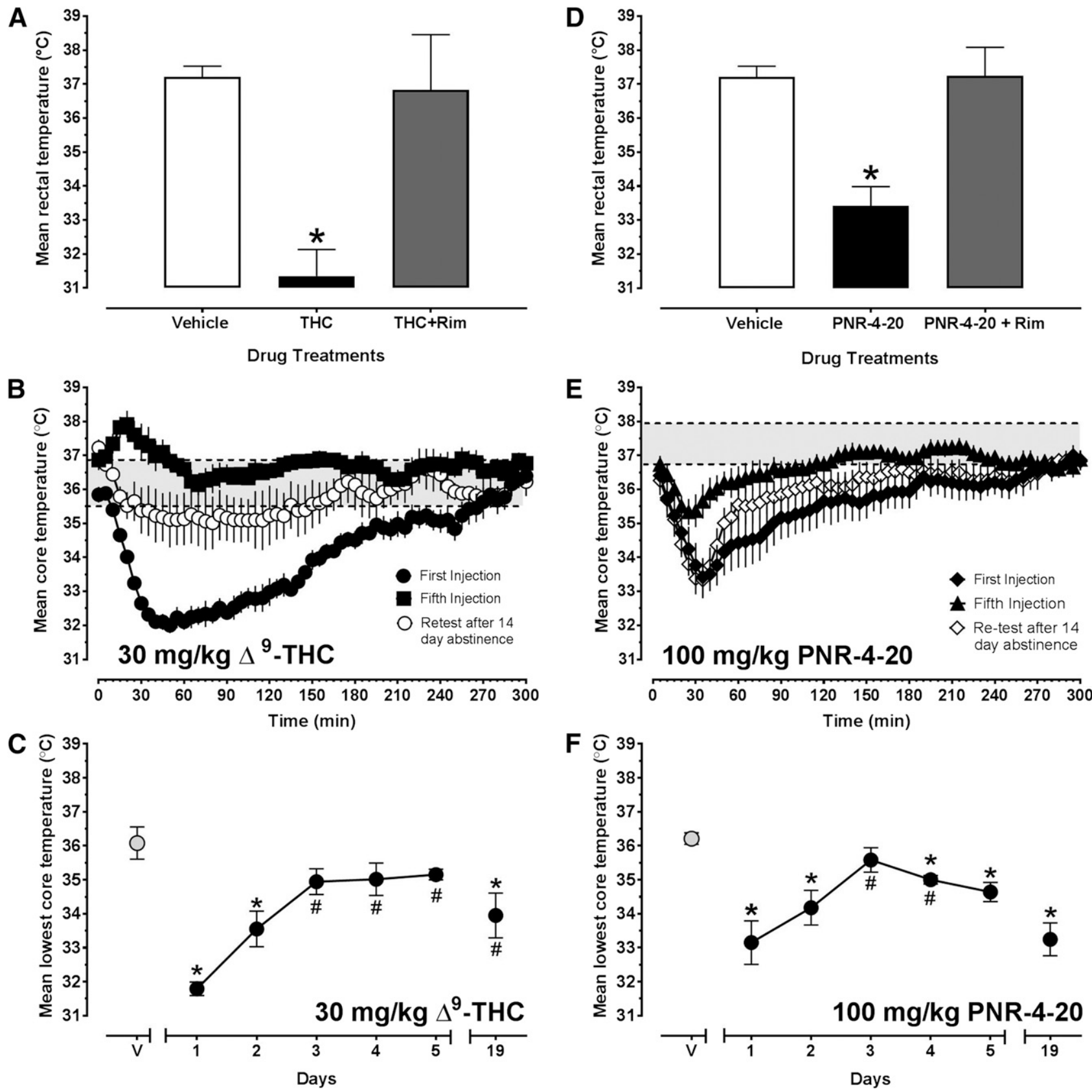

Fig. 1. (A) Effects of vehicle (open bar), $30 \mathrm{mg} / \mathrm{kg} \Delta^{9}$-THC (black bar), or $10 \mathrm{mg} / \mathrm{kg}$ rimonabant $+\Delta^{9}-\mathrm{THC}$ (gray bar) on rectal temperature, measured (in degrees Celsius) 60 minutes after injection. Bars represent group mean \pm S.E.M. values. Asterisks indicate significant differences from vehicle $(P<$ 0.05). (B) Time-activity curves for hypothermic effects of $30 \mathrm{mg} / \mathrm{kg} \Delta^{9}-\mathrm{THC}$ following the first (filled circles) and fifth daily injections (filled squares), and then again when tested after a 14-day drug abstinence period (open circles) as measured in degrees Celsius by radiotelemetry. Points represent group mean \pm S.E.M. values, and any points without error bars indicate that the variability is contained within the point. The shaded area between the dotted lines represents the range of core temperatures recorded over 24 hours following vehicle administration. (C) Lowest core temperatures recorded in degrees Celsius following injection of vehicle or repeated daily administration of $30 \mathrm{mg} / \mathrm{kg} \Delta^{9}$-THC for five consecutive days and then again after a 14 -day drug abstinence period. Points represent group mean \pm S.E.M. values, and any points without error bars indicate that the variability is contained within the point. The gray-filled point above the letter $\mathrm{V}$ indicates the mean lowest temperature recorded within 3 hours of vehicle administration. Asterisks indicate significant differences from vehicle, while hashtags indicate significant differences from $\Delta^{9}$-THC day $1(P<0.05)$. (D) Effects of vehicle (open bar), $100 \mathrm{mg} / \mathrm{kg}$ PNR-4-20 (black bar), or $10 \mathrm{mg} / \mathrm{kg}$ rimonabant + PNR-4-20 (gray bar) on rectal temperature, measured (in degrees Celsius) $60 \mathrm{minutes}$ after injection. All other graph properties as described in (A). (E) Time-activity curves for hypothermic effects of $100 \mathrm{mg} / \mathrm{kg}$ PNR-4-20 following the first (filled diamonds) and fifth daily injections (filled triangles), and then again when tested after a 14-day drug abstinence period (open diamonds) as measured in degrees Celsius by radiotelemetry. All other graph properties as described in (B). (F) Lowest core temperatures recorded in degrees Celsius following injection of vehicle or repeated daily administration of $100 \mathrm{mg} / \mathrm{kg}$ PNR-4-20 for five consecutive days and then again after a 14-day drug abstinence period. All other graph properties as described in (C).

Following the initial injection, the core temperature dropped by $\sim 3^{\circ} \mathrm{C}$; however, since mice were repeatedly treated every 24 hours for the remaining 4 days, an unusual pattern of acute tolerance development emerged (Fig. $1 \mathrm{~F}$ ). As with $\Delta^{9}$-THC, the first $(q=8.623 ; P<0.05)$ and second $(q=5.734 ; P<0.05)$ PNR-4-20 injections elicited hypothermic effects that were 
different from those observed following vehicle injection, while the third ( $q=6.855 ; P<0.05$ ) injection elicited effects that were significantly different from those observed after the first PNR-4-20 administration but were not different from the vehicle control $(q=1.769 ; P>0.05)$. Interestingly, the fourth and fifth PNR-4-20 injections again elicited hypothermic effects that were different from the vehicle control $(q=$ 4.727 for injection 4 and $q=4.945$ for injection $5 ; P<0.05$ for both comparisons), but were also significantly different from the hypothermic effects observed following the initial administration of the drug $(q=5.216$ for injection 4 and $q=$ 4.624 for injection $5 ; P<0.05$ for both comparisons). No other between-day comparisons were significant during this 5-day period of repeated drug administration. After the 14-day drug abstinence period, PNR-4-20 elicited hypothermic effects that were significantly different from the vehicle control $(q=3.353$; $P<0.05)$ but not from the initial drug administration $(q=$ $0.270 ; P>0.05)$, with $E_{\max }$ and $t_{\max }$ values also similar to those observed after the initial treatment (Fig. 1F; Table 1). Thus, PNR-4-20 and $\Delta^{9}$-THC both produced $\mathrm{CB}_{1}$ R-mediated hypothermia in vivo, but distinctions in both acute and persistent tolerance were observed between these drugs.

Mice Chronically Treated with $100 \mathrm{mg} / \mathrm{kg}$ PNR-4-20 Exhibited Less Tolerance to Cannabinoid-Induced Antinociception and Catalepsy. In antinociception studies (Fig. 2A), significant effects of drug $[F(3,100)=85.677]$ and day $[F(5,100)=52.120]$ were observed, and the interaction between these two factors was also significant $[F(15,100)=$ 4.573; $P<0.05$ for all comparisons]. Following repeated vehicle injection (Fig. 2A, open circles), no significant differences in tail withdrawal latencies were observed across days $\left(P>0.05\right.$ for all comparisons.) For daily $\Delta^{9}$-THC administrations (Fig. 2A, filled circles), significant differences from the vehicle controls were observed on days $1(q=12.572)$ and $2(q=5.944)$, and the initial antinociceptive effect noted on day 1 was significantly different from that observed on days $2(q=6.678), 3(q=10.401), 4(q=10.707)$, and $5(q=10.973)$ $(P<0.05$ for all comparisons). The antinociceptive effect noted on day 2 was also different from that observed on day 5 ( $q=$ 4.294; $P<0.05$ ), but no other between-day comparisons were significant during this 5 -day period of repeated $\Delta^{9}$-THC administration. For daily JWH-018 administrations (Fig. $2 \mathrm{~A}$, filled triangles), significant differences from the vehicle controls were observed on days $1(q=11.936), 2(q=8.372)$, $3(q=4.621)$, and $4(q=4.145)$, and the initial antinociceptive effect noted on day 1 was significantly different from that observed on days $3(q=7.433), 4(q=8.867)$, and $5(q=10.847)$ ( $P<0.05$ for all comparisons). The antinociceptive effect noted on day 2 was also different from that observed on days 4 ( $q=$ $5.282)$ and 5 ( $q=7.262)(P<0.05$ for both comparisons), but no other between-day comparisons were significant during this 5-day period of repeated JWH-018 administration. For daily PNR-4-20 administrations (Fig. 2A, open diamonds), significant differences from the vehicle controls were observed on days $1(q=9.427), 2(q=6.741)$, and $4(q=5.875)$, and the initial antinociceptive effect noted on day 1 was significantly different from that observed on days $3(q=6.558), 4(q=$ 4.588), and 5 ( $q=6.697$ ) ( $P<0.05$ for all comparisons). No other between-day comparisons were significant during this 5-day period of repeated PNR-4-20 administration. Interestingly, when animals were retested after a 7-day drug abstinence period, residual tolerance was apparent for animals
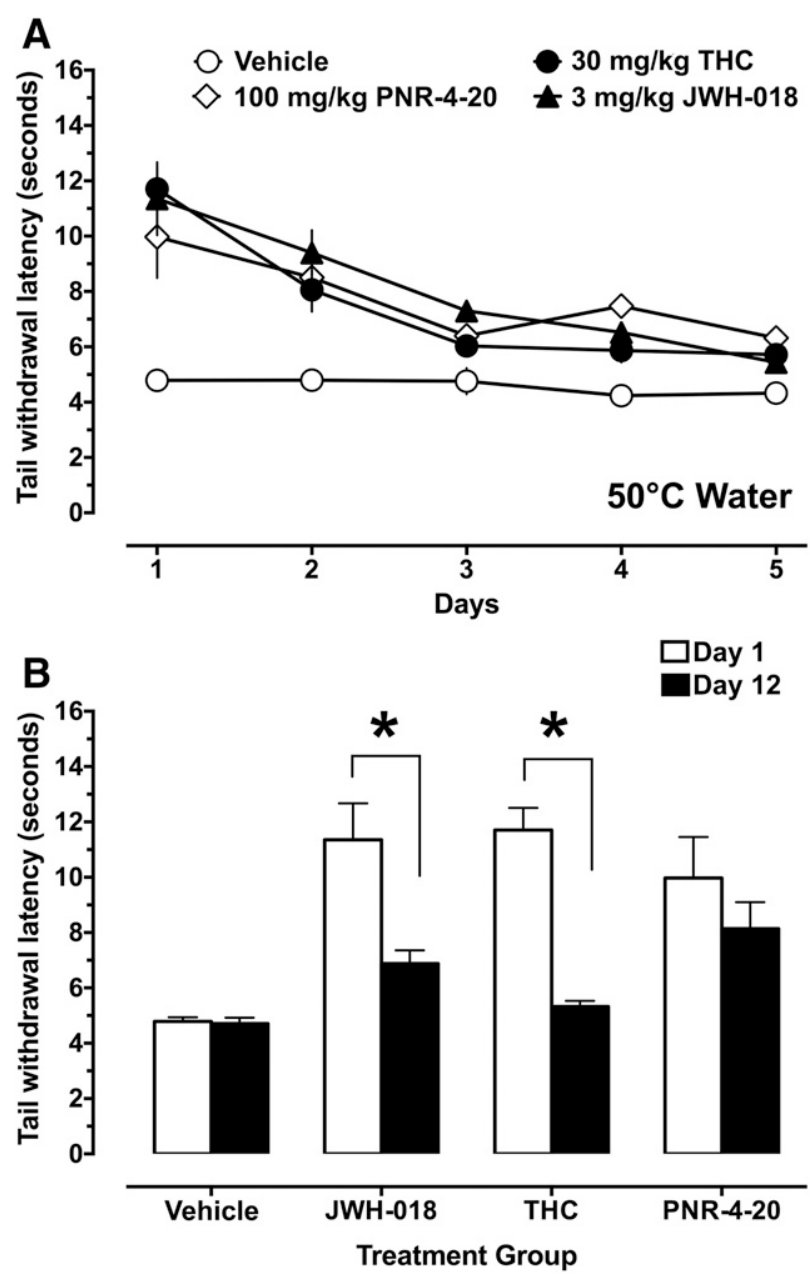

Fig. 2. (A) Effects of daily vehicle (open circles), $30 \mathrm{mg} / \mathrm{kg} \Delta^{9}-\mathrm{THC}$ (filled circles), $3 \mathrm{mg} / \mathrm{kg}$ JWH-018 (open triangles), or $100 \mathrm{mg} / \mathrm{kg}$ PNR-4-20 (open diamonds) on tail withdrawal latency from $50^{\circ} \mathrm{C}$ water across 5 days. For statistical comparisons, please see Results. All other graph properties as described in Fig. 1. (B) Antinociceptive effects of vehicle, $30 \mathrm{mg} / \mathrm{kg} \Delta^{9}$-THC, $3 \mathrm{mg} / \mathrm{kg}$ JWH-018, or $100 \mathrm{mg} / \mathrm{kg}$ PNR-4-20 on the first administration (open bars) and final test administration after a 7-day abstinence period (filled bars.) Asterisks represent significant differences in tail withdrawal latency between day 1 and drug retest day after a 7-day abstinence period. All other graph properties as described in Fig. 1.

treated with JWH-018 and $\Delta^{9}$-THC (Fig. 2B) but not in mice treated with PNR-4-20. Tail withdrawal latencies significantly less than those observed following the first drug administration were quantified after the abstinence period for $\Delta^{9}$-THC $(q=11.697)$ and JWH-018 $(q=8.210)(P<0.05$ for both comparisons), but not for PNR-4-20 ( $q=2.399 ; P>0.05)$.

To study the cataleptic effects of JWH-018, $\Delta^{9}$-THC, and PNR-4-20 across repeated treatments, mice were injected as described previously. Because habituation to the testing procedure over repeated days confounds the results, mice were only tested on the horizontal bar on days 1 and 5 , and then again after the 7-day abstinence period on day 12. Animals repeatedly treated with JWH-018 showed pronounced tolerance to cataleptic effects on day $5(t=5.772, P<0.05)$, and this tolerance was still apparent during the retest on day $12(t=$ 5.433, $P<0.05$ ) (Fig. 3). Similarly, repeated testing with $\Delta^{9}$ THC resulted in reduced catalepsy scores on days 5 and 12 , although large intersubject variability in the initial catalepsy scores observed on day 1 precluded statistical significance. 


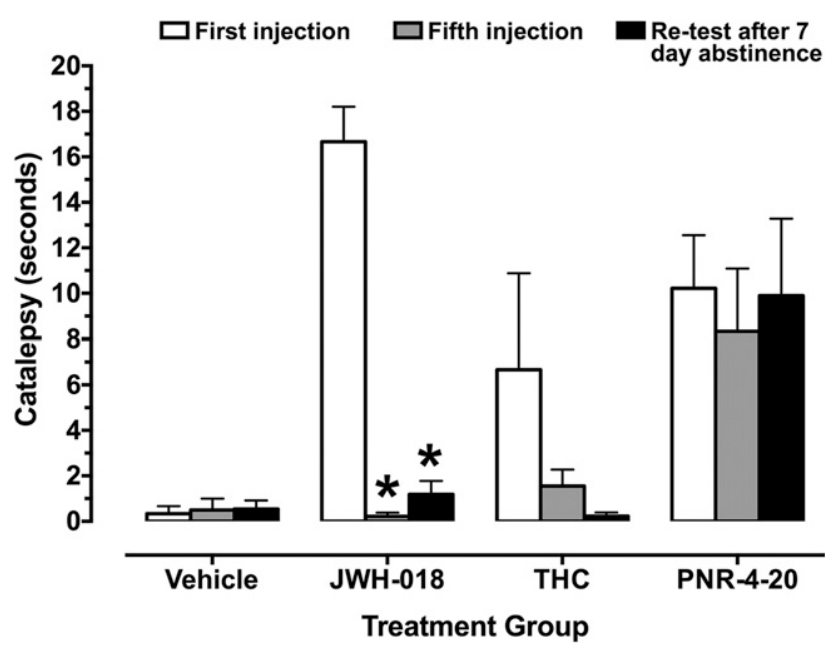

Fig. 3. Cataleptic effects of vehicle, $3 \mathrm{mg} / \mathrm{kg}$ JWH-018, $30 \mathrm{mg} / \mathrm{kg} \Delta^{9}$-THC, or $100 \mathrm{mg} / \mathrm{kg}$ PNR-4-20 assessed following the first (open bars) and fifth (gray bars) daily injections, and following a retest after a 7-day drug abstinence period (black bars.) Asterisks represent catalepsy scores that differ significantly from those observed on day 1 , for a given treatment condition. All other graph properties as described in Fig. 1.

In contrast, PNR-4-20 elicited cataleptic effects at a similar level across the three tests, and no apparent tolerance was observed on days 5 or 12 .

Crosstolerance to Hypothermic Effects among PNR-4-20 and $\Delta^{\mathbf{9}}$-THC. Because PNR-4-20 elicits a distinct tolerance profile across repeated administration in mice, the potential for crosstolerance to cannabinoid-induced hypothermia between PNR-4-20 and $\Delta^{9}$-THC was investigated. Figure $4 \mathrm{~A}$ presents time-activity data for core temperature following injection of PNR-4-20 on days 1 and 4, with $\Delta^{9}$-THC being administered on day 5 . Statistical analysis of the lowest core temperature observed across all treatment days (Fig. 4B) detected hypothermic effects of all PNR-4-20 administrations when compared with the vehicle control $(q=13.779,7.504$, 6.288 , and 5.752 for injections $1-4$, respectively; $P<0.05$ for all comparisons) and for the $\Delta^{9}$-THC crosstolerance test on day 5 ( $q=8.975, P<0.05)$. However, hypothermic effects elicited by the initial injection of PNR-4-20 significantly differed from those of all subsequent drug administrations $(q=6.275$ for injection $2, q=7.491$ for injection $3, q=8.027$ for injection 4 , and $q=4.804$ for the $\Delta^{9}$-THC crosstolerance test on day $5 ; P<$ 0.05 for all comparisons). Importantly, challenge with $\Delta^{9}$-THC on day 5 revealed apparent hypothermic effects with maximal temperature reductions similar to those observed following the final dose of PNR-4-20, but with a much longer duration of action (see Table 2), similar to that typically observed with an initial administration of $\Delta^{9}$-THC to drug-naive mice.

Similarly, Fig. 4C presents time-activity data for core temperature following injection of $\Delta^{9}$-THC for days 1 and 4 with PNR-4-20 being administered on day 5. Statistical analysis of the lowest core temperature observed across all treatment days (Fig. 4D) detected hypothermic effects of the first two injections of $\Delta^{9}$-THC when compared with the vehicle control ( $q=9.399$ and 5.399, respectively; $P<0.05$ for both comparisons), but not for days 3 or $4(q=4.022$ and 3.045, respectively; $P>0.05$ for both comparisons.) During the crosstolerance test with PNR-4-20 on day 5, no significant hypothermic effects were observed ( $q=3.124 ; P>0.05)$.
However, hypothermic effects elicited by the initial injection of $\Delta^{9}$-THC significantly differed from those of the third and fourth drug administrations $(q=5.377$ and 6.354, respectively; $P<0.05$ for both comparisons), as did the hypothermic effects induced by the PNR-4-20 crosstolerance test on day $5(q=6.275 ; P<0.05)$. Importantly, administration of PNR-4-20 on the last day induced hypothermic effects that were not significantly different from those produced by the fourth $\Delta^{9}$-THC injection, despite the higher in vitro efficacy of PNR-4-20 at $\mathrm{CB}_{1} \mathrm{Rs}_{\mathrm{s}}$ (see Table 2). Collectively, these data suggest an asymmetric crosstolerance among $\Delta^{9}$ THC and PNR-4-20, since animals administered PNR-4-20 for 4 days showed significant hypothermia when challenged with $\Delta^{9}$-THC, while animals repeatedly administered $\Delta^{9}$-THC and challenged with PNR-4-20 did not.

Repeated Treatment with PNR-4-20 Produces Less $\mathrm{CB}_{1} \mathrm{R}$ Downregulation in the Hypothalamus and Thalamus than the Unbiased Agonist $\boldsymbol{\Delta}^{\mathbf{9}}$-THC. Prolonged treatment with $\Delta^{9}-\mathrm{THC}$ in naive mice resulted in $64 \%$ and $74 \%$ reductions in $\mathrm{CB}_{1} \mathrm{R}$ expression (e.g., $B_{\max }$ values) in the hypothalamus (Fig. 5A) and thalamus (Fig. 5B), respectively, relative to vehicle-treated animals $(q=10.200$ and 5.812, respectively; $P<0.05$ for both comparisons). Repeated PNR-420 treatment also significantly reduced $C_{1} R$ levels relative to vehicle in the hypothalamus (Fig. 5A, $q=4.549$ and $P<0.05$ ), but the degree of downregulation was significantly less than that produced by $\Delta^{9}$-THC $(q=5.655 ; P<0.05)$. Interestingly, in the thalamus, chronic PNR-4-20 treatment did not significantly reduce $\mathrm{CB}_{1} \mathrm{R}$ density $(q=1.359 ; P>0.05)$. Despite the alterations in $B_{\max }$, no treatment produced a significant alteration in the affinity (e.g., $K_{\mathrm{d}}$ values) of CP 55,940 in either brain region studied (see Table 3 ).

\section{Discussion}

Drugs that selectively signal through G protein-dependent pathways can elicit therapeutic effects with reduced adverse effects. As seen with the $\mathrm{G}$ protein-biased $\mu$-opioid agonist oliceridine (formerly TRV130), antinociception can be induced with minimal adverse effects associated with acute (i.e., gastrointestinal inhibition and respiratory depression) or chronic (i.e., analgesic tolerance) administration (Soergel et al., 2014). Additionally, the G protein-biased $\kappa$-opioid agonist triazole 1.1 produced antinociceptive and antipruritic effects without inducing significant sedation or dysphoria (Brust et al., 2016). We believe IQD-derived PNR-4-20 is the first $\mathrm{G}$ protein-biased cannabinoid agonist developed; however, despite the precedent set by the biased opioid agonists, the data here presented for PNR-4-20 only partially follow this pattern of preserved therapeutic effects with reduced adverse effects.

In this regard, acute antinociceptive effects of PNR-4-20 were obtained in the warm water tail withdrawal assay, and these effects were similar in magnitude to those of the unbiased cannabinoid agonists $\Delta^{9}$-THC and JWH-018, suggesting that the reduced recruitment of $\beta$-arrestins by PNR-420 may not impair its therapeutic utility in the realm of pain management. However, antinociceptive tolerance was clearly observed with chronic administration of PNR-4-20, and this progressive reduction in effect occurred at a similar rate and to a similar extent as seen with unbiased $\Delta^{9}$-THC and JWH-018. However, it is important to note that imposition of a drug 
A

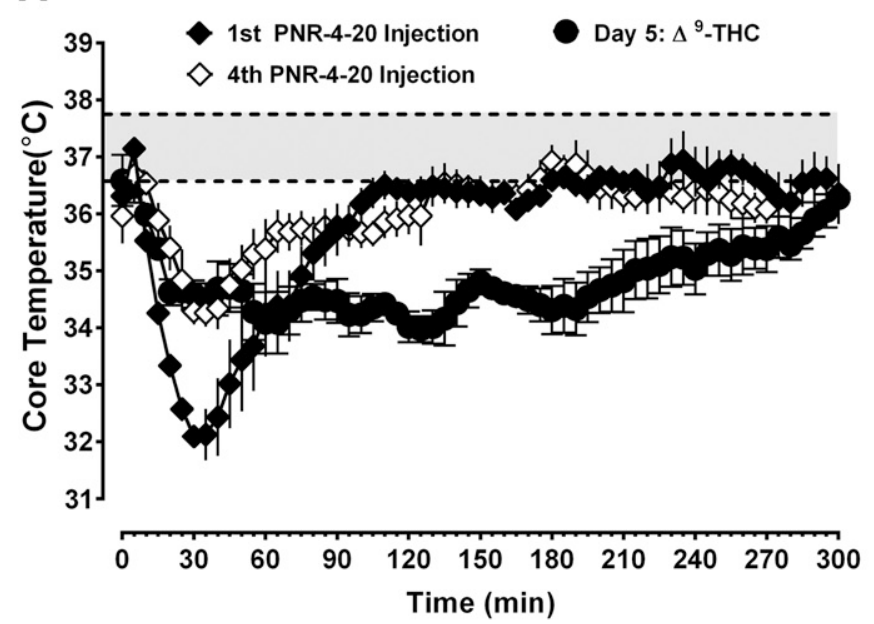

C

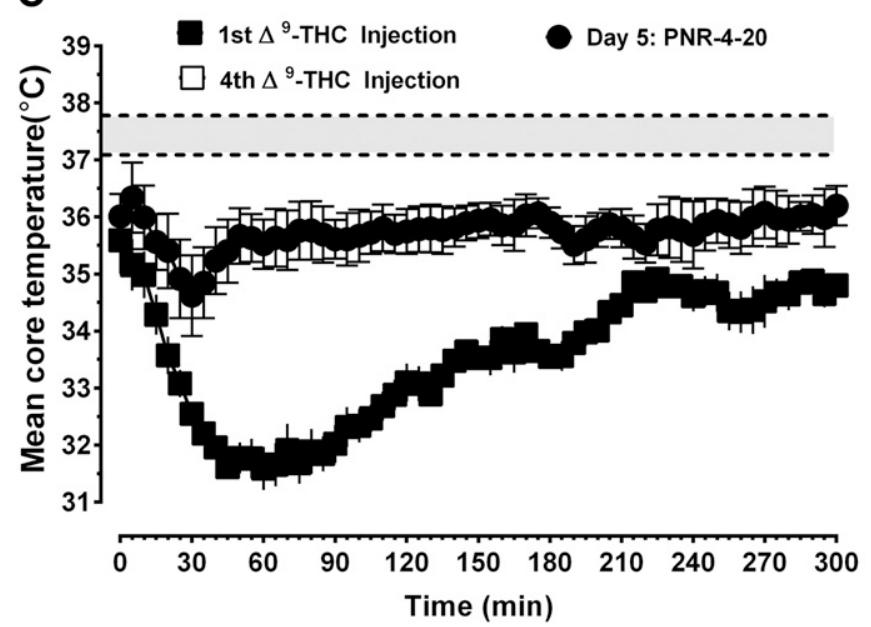

B

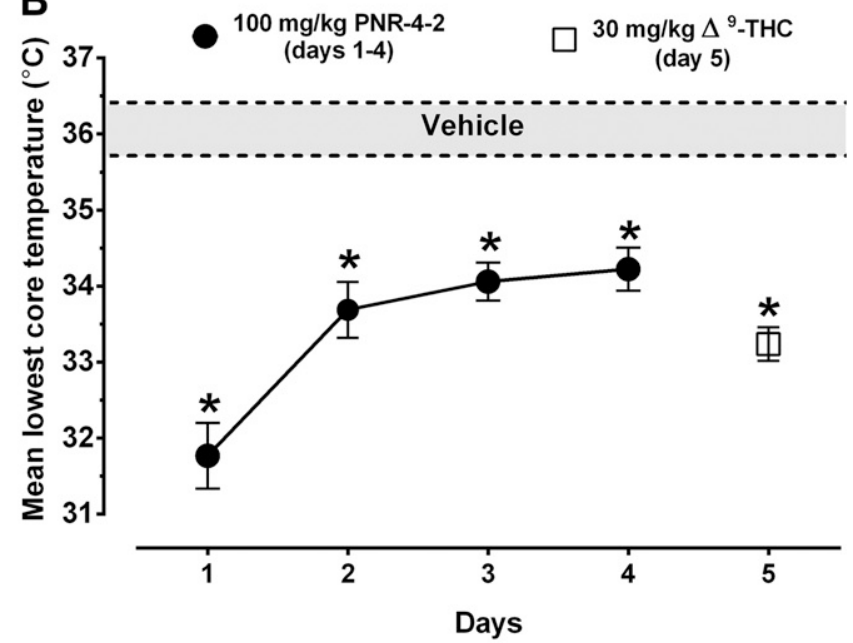

D

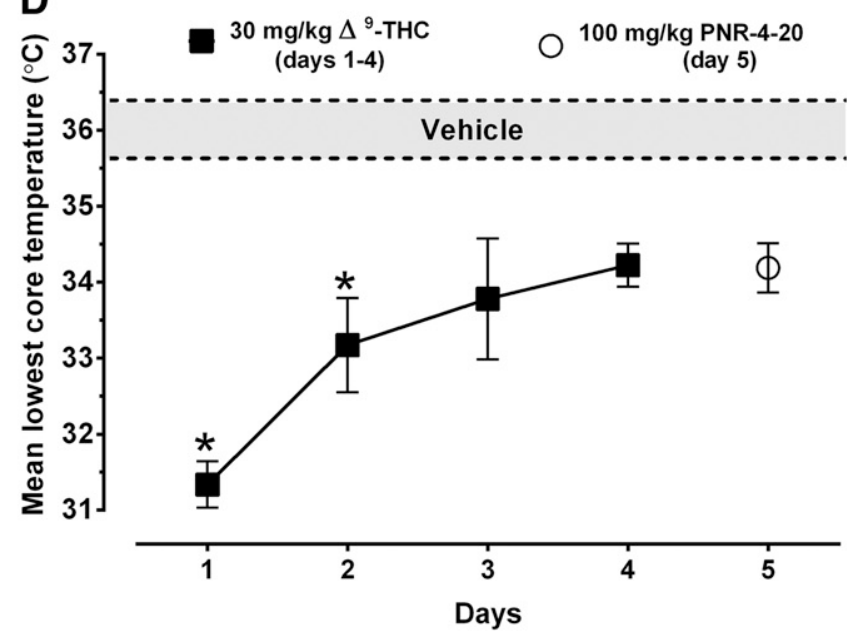

Fig. 4. (A) Time-activity curves for hypothermic effects of $100 \mathrm{mg} / \mathrm{kg}$ PNR-4-20 following the first (filled diamonds) and fourth (open diamonds) daily injections, and then for a crosstolerance test with $30 \mathrm{mg} / \mathrm{kg} \Delta^{9}-\mathrm{THC}$ on day 5 (filled circles) as measured in degrees Celsius by radiotelemetry. All other graph properties as described in Fig. 1. (B) Lowest core temperatures recorded in degrees Celsius following repeated daily administration of $100 \mathrm{mg} / \mathrm{kg}$ PNR-4-20 for four consecutive days (filled circles), and then for a crosstolerance test with $30 \mathrm{mg} / \mathrm{kg} \Delta^{9}$-THC on day 5 (open square). Asterisks indicate significant differences from vehicle, while hashtags indicate significant differences from day $1(P<0.05)$. All other graph properties as described in Fig. 1. (C) Time-activity curves for hypothermic effects of $30 \mathrm{mg} / \mathrm{kg} \Delta^{9}$-THC following the first (filled squares) and fourth (open squares) daily injections, and then for a crosstolerance test with $100 \mathrm{mg} / \mathrm{kg}$ PNR-4-20 on day 5 (filled circles) as measured in degrees Celsius by radiotelemetry. All other graph properties as described in Fig. 1. (D) Lowest core temperatures recorded in degrees Celsius following repeated daily administration of $30 \mathrm{mg} / \mathrm{kg} \Delta^{9}$-THC for four consecutive days (filled squares), and then for a crosstolerance test with $100 \mathrm{mg} / \mathrm{kg}$ PNR-4-20 on day 5 (open circle). Asterisks indicate significant differences from vehicle, while hashtags indicate significant differences from day $1(P<0.05)$. All other graph properties as described in Fig. 1.

abstinence period no longer than 7 days was sufficient to completely restore antinociceptive efficacy of PNR-4-20, and this was dramatically different from the persistent tolerance to antinociceptive effects observed with the same chronic regimens of comparably effective doses of $\Delta^{9}$-THC and JWH018. A similar distinction can be drawn between the cataleptic effects of PNR-4-20, $\Delta^{9}$-THC, and JWH-018, since no apparent tolerance was observed with PNR-4-20 on this endpoint, while complete and persistent tolerance was observed with the two unbiased cannabinoid agonists. Although cannabinoidelicited catalepsy is not a particularly useful therapeutic effect, the complete lack of tolerance development here observed with PNR-4-20 lends proof-of-concept credence to the notion that $\mathrm{G}$ protein-biased agonists may be capable of circumventing the standard progressive reduction in effect observed with chronic administration of unbiased cannabinoid agonists. Future drug design efforts with the IQD scaffold may identify novel compounds that resist tolerance to more therapeutically relevant endpoints, such as antinociceptive effects.

While it is possible that a shorter duration of hypothermic action for PNR-4-20 relative to tetrahydrocannabinol (THC) might constitute a potential mechanism to explain the reduced tolerance presented here, we believe that this is unlikely for two reasons. First, we have previously reported that similar to the PNR-4-20 results given here, JWH-018 also exhibits a shorter duration of action in the cannabinoid tetrad relative to THC (Brents et al., 2011), but elicits similar tolerance development to hypothermic effects as that observed with THC (Tai et al., 2015). Nevertheless, the duration of PNR-4-20-elicited hypothermic effects is shorter than that of JWH-018, and the maximal hypothermic effects of PNR-4-20 (at doses straining the limit of solubility) are smaller in magnitude than those of JWH-018. In agreement with those 
A

Hypothalamus

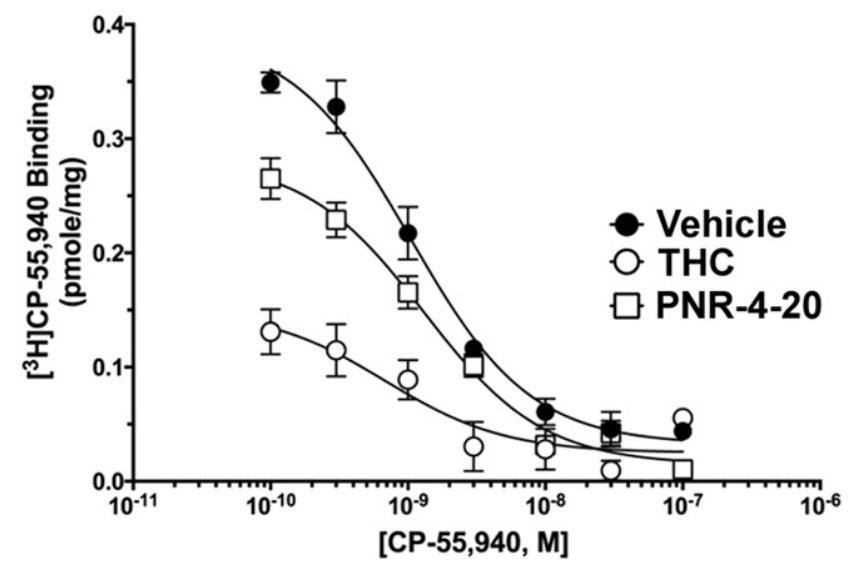

B

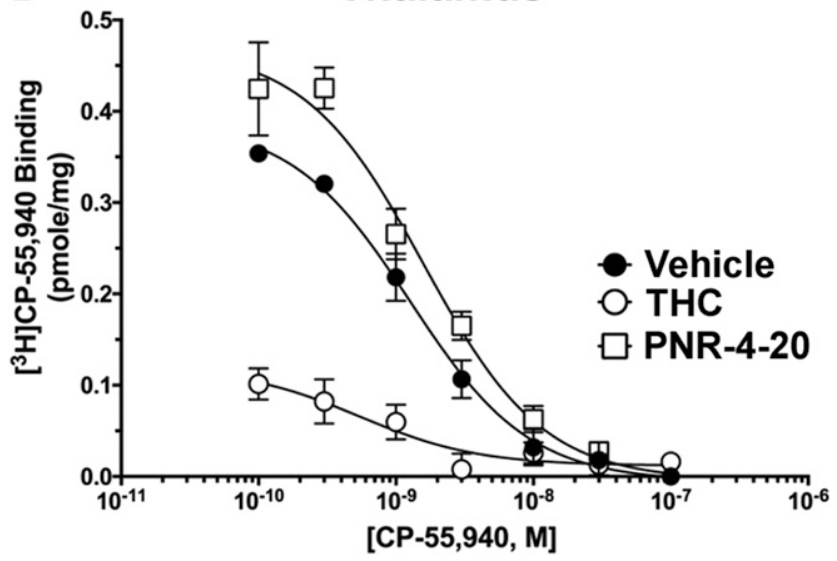

Fig. 5. Homologous binding curves for CP 55,940 in hypothalamus (A) or thalamus (B) collected from mice previously treated with vehicle (filled circles), $30 \mathrm{mg} / \mathrm{kg} \Delta^{9}$-THC (open circles), or $100 \mathrm{mg} / \mathrm{kg}$ PNR-4-20 (open squares) once per day for five consecutive days. Points represent group mean \pm S.E.M. values, and any points without error bars indicate that the variability is contained within the point. $\left[{ }^{3} \mathrm{H}\right] \mathrm{CP} 55,940$ homologous binding was used to determine $K_{\mathrm{d}}$ and $B_{\max }$ values reported in Table 3.

previous studies, and despite differences in their durations of action, we report in the present study (Fig. 2) that both JWH-018 and THC produce greater levels of tolerance relative to PNR-4-20. Second, the AUC for hypothermic effects elicited by THC (Fig. 1B) and PNR-4-20 (Fig. 1E) on day 1 of treatment were not significantly different from one another. Although additional pharmacokinetic studies of PNR-4-20 could potentially add mechanistic insight, the data presented here were primarily designed only as an initial study to compare the in vitro versus in vivo effects of the first $G$ protein-biased $C_{1} R$ agonist to unbiased $C_{1} B_{1} R$ agonists. Importantly, the purpose of these designed studies was met by the data presented (e.g., demonstrating differences between biased and unbiased $\mathrm{CB}_{1} \mathrm{R}$ agonists). Nevertheless, we believe that comprehensive pharmacokinetic studies should be conducted with PNR-4-20 and other novel compounds exhibiting $\mathrm{G}$ protein bias at $\mathrm{CB}_{1} \mathrm{Rs}$ as part of future drug development efforts.

Studies investigating crosstolerance between PNR-4-20 and $\Delta^{9}$-THC further revealed novel in vivo functionality of our lead compound. Data from these studies suggest that the hypothermic effects of both PNR-4-20 and $\Delta^{9}$-THC diminished over repeated administration; however, while complete and persistent tolerance to hypothermic effects of $\Delta^{9}$-THC were apparent, significant hypothermic effects of PNR-4-20 re-emerged with continued treatment, and no evidence of residual tolerance was observed when animals were tested again after a 14-day drug abstinence period. This represents a dramatic difference between the effects of chronic $\Delta^{9}$-THC and PNR-4-20, which is further reflected in the nonreciprocal crosstolerance observed between these two drugs. Specifically, administration of $\Delta^{9}$-THC to mice previously treated with PNR-4-20 for four consecutive days resulted in significant hypothermic effects that were comparable (in terms of duration) to those observed following administration of $\Delta^{9}$-THC to drug-naive mice. On the other hand, administration of PNR-420 to mice previously treated with $\Delta^{9}$-THC resulted in an attenuated hypothermic effect that was not statistically distinguishable from injection of the drug vehicle. This later finding is not necessarily surprising, since the aminoalkylindole full $\mathrm{CB}_{1} \mathrm{R}$ agonists JWH-018 and (1-butyl_iH-indol-3-yl) (1-naphthyl)methanone (JWH-073) both also failed to surmount tolerance to hypothermic effects (measured as core temperature with radiotelemetry) elicited by $\Delta^{9}$-THC in National Institutes of Health Swiss mice treated identically to those in the present studies (Tai et al., 2015); however, tolerance to hypothermic effects elicited by a different chronic regimen of $\Delta^{9}$-THC (measured as rectal temperature by insertion of a thermoprobe) were partially surmounted by administration of structurally distinct $\mathrm{CB}_{1} \mathrm{R}$ high-efficacy agonists WIN 55,212 and CP 55,940 in ICR mice (Fan et al., 1994). Because cannabinoid agonists typically desensitize and downregulate $\mathrm{CB}_{1} \mathrm{Rs}$ through recruitment of $\beta$-arrestins, it is expected that treatment with any unbiased agonist would likely decrease the effects of subsequent treatment with a different agonist. However, the pattern of data obtained here suggests that the effects of repeated exposure to PNR-4-20 results in different regulatory effects on $\mathrm{CB}_{1} \mathrm{Rs}$ than the effects typically observed with unbiased agonists such as $\Delta^{9}$-THC. This is supported by our present data demonstrating that chronic PNR-4-20, at the doses tested here, elicits absolutely no downregulation of $\mathrm{CB}_{1} \mathrm{Rs}$ in the thalamus and dramatically attenuated downregulation of $\mathrm{CB}_{1} \mathrm{Rs}$ (compared with $\Delta^{9}$-THC) in the hypothalamus.

The $\mathrm{CB}_{1} \mathrm{R} / \mathrm{CB}_{2} \mathrm{R}$ agonist $\left[{ }^{3} \mathrm{H}\right] \mathrm{CP} 55,940$ was used to quantify $\mathrm{CB}_{1} \mathrm{R}$ downregulation in this study. As an agonist, this radioligand can exhibit biphasic binding kinetics, binding to both high- and low-affinity states of the receptor. It is possible that the repeated drug treatment in the present study may have reduced the pool of $G$ proteins available for receptor coupling and/or affected coupling of $\mathrm{G}$ proteins to the receptor. If so, this might be reflected as an apparent decrease in receptor binding, even though it would actually represent only a decrease in proportion of receptors in the high-affinity state and not in the total receptor number. Therefore, it cannot conclusively be stated that the reductions in $B_{\max }$ observed are due solely to receptor downregulation, since changes in receptor/G protein stoichiometry and receptor desensitization could affect high-affinity binding and appear as a decrease in $B_{\max }$. The question could be conclusively answered by future studies using antagonist radioligands to quantify receptor density, which typically exhibit similar affinity for both lowand high-affinity sites. 
TABLE 3

Affinity and $B_{\max }$ values of hypothalamus and thalamus brain membranes in mice repeatedly treated with vehicle, $\Delta^{9}$-THC, and PNR-4-20

The $\mathrm{p} K_{\mathrm{d}}$ and $B_{\max }$ values calculated from the homologous binding curves for CP 55,940 in hypothalamus and thalamus are presented in Fig. 5. Brain regions were collected from mice previously treated with vehicle (Fig. 5, filled circles), $30 \mathrm{mg} / \mathrm{kg}$ $\Delta^{9}$-THC (Fig. 5, open circles), or $100 \mathrm{mg} / \mathrm{kg}$ PNR-4-20 (Fig. 5, open squares) once per day for five consecutive days. The S.E. M. for both the $B_{\max }$ and $K_{\mathrm{d}}$ values was derived from averaging the values of each curve fit for each replication, and these S.E. values were used for the ANOVA. The $\mathrm{p} K_{\mathrm{d}}$ and $B_{\max }$ values not sharing a letter are significantly different from each other, within each respective brain region, as indicated by one-way ANOVA and Tukey's honest significant difference post-hoc test. $N$ denotes number of subjects.

\begin{tabular}{lcccccc}
\hline \multirow{2}{*}{ Treatment } & \multicolumn{5}{c}{$\left[{ }^{3} \mathrm{H}\right] \mathrm{CP} 55,940$ Binding } \\
\cline { 2 - 6 } & $K_{\mathrm{d}}$ & $K_{\mathrm{d}}(95 \% \mathrm{CI})$ & $\mathrm{p} K_{\mathrm{d}}\left(-\mathrm{Log}\left[\mathrm{K}_{\mathrm{d}}\right]\right)$ & $B_{\max }$ & $B_{\max }(95 \% \mathrm{CI})$ & $N$ \\
\hline & $n M$ & & $p m o l / m g$ \\
\\
Hypothalamus
\end{tabular}

CI, confidence interval.

We have previously demonstrated that the G protein versus $\beta$-arrestin 2 bias factor for PNR-4-20 was 29.5, which compares quite favorably with the $\mathrm{G}$ protein bias factors reported for other drugs, such as the bias factor of $\sim 3$ reported for oliceridine. Nevertheless, the initial tolerance development to antinociceptive and hypothermic effects of PNR-4-20 is perhaps explainable by the in vitro observations that repeated treatment with PNR-420 did result in rapid recruitment of $\beta$-arrestin 2 , producing desensitization and downregulation of $\mathrm{CB}_{1} \mathrm{Rs}$ (Ford et al., 2017). Importantly, PNR-4-20-treated cells, but not CP 55,940-treated cells, recovered from agonist-induced desensitization and downregulation at later timepoints. While comprehensive studies investigating downstream signaling cascades have yet to be conducted with PNR-4-20 at $\mathrm{CB}_{1} \mathrm{Rs}$, these studies would likely provide mechanistic explanations for the lack of persistent tolerance to PNR-4-20 effects such as those presently demonstrated in mice, and may also explain the apparent reversal of tolerance to hypothermic effects demonstrated here.

We have previously demonstrated orderly dose-effect relationships for PNR-4-20 in the cannabinoid tetrad in mice, and shown that these effects are blocked by prior administration of the $\mathrm{CB}_{1} \mathrm{R}$ inverse agonist/antagonist rimonabant (Ford et al., 2017). Nevertheless, the relatively poor solubility of PNR-4-20 probably prevents us from capturing the true maximal effects of this drug in vivo, since we routinely observe larger hypothermic effects with aminalkylindole-derived synthetic cannabinoid agonists with similar efficacy (in terms of $\mathrm{G}$ protein signaling) as PNR-4-20 (e.g., Tai et al., 2015). To address this issue, other $\mathrm{CB}_{1} \mathrm{R}$ G protein-biased IQD analogs such as PNR-4-02 (Ford et al., 2017) should be considered for further in vivo analysis. Characterizing the in vivo profile of multiple IQD analogs could potentially aid in the development of $\mathrm{G}$ protein-biased compounds that have improved drug-like properties. Additionally, studies investigating downregulation and desensitization of $\mathrm{CB}_{1} \mathrm{Rs}$ in mice repeatedly treated with PNR-4-20 also need to be expanded upon. Specifically, only homologous receptor binding was performed on hypothalamus and thalamus brain regions. While measurements of receptor density are important in determining changes in $\mathrm{CB}_{1} \mathrm{R}$ expression, functional assays measuring $\mathrm{G}$ protein function and downstream effector modulation should be conducted in future experiments to determine if receptor desensitization occurs following repeated dosing of PNR-4-20. While $\mathrm{CB}_{1} \mathrm{Rs}$ in the hypothalamus and thalamus mediate temperature regulation as well as pain perception (Cross, 1994; Martin et al., 1996; Fonseca et al., 2014), other brain regions associated with nociception and catalepsy (e.g., spinal cord, periaqueductal gray, caudate-putamen, and globus pallidus) should be investigated as well.

Alongside exploratory mechanistic studies of PNR-4-20, additional in vivo studies investigating the potential abuse liability of the IQD drug class using drug discrimination and self-administration assays should be conducted. Because PNR4-20 exhibits a distinct pharmacological profile at $\mathrm{CB}_{1} \mathrm{Rs}$, most likely related to its $\mathrm{G}$ protein-biased agonism, substituting PNR-4-20 in a drug discrimination assay where subjects have been trained to discriminate $\Delta^{9}$-THC from saline would potentially reveal whether the interoceptive effects of this novel compound are similar to or distinct from those of traditional unbiased cannabinoids. As previously established with JWH018 and JWH-073 in mice that were trained to discriminate $\Delta^{9}$ THC from saline, cannabinoid agonists with differing intrinsic $\mathrm{CB}_{1} \mathrm{R}$ efficacies nonetheless cross-substitute for one another in drug discrimination assays (Wiley et al., 2014). Whether this also applies to $\mathrm{CB}_{1} \mathrm{R}$ agonists with different signaling profiles remains to be determined. Furthermore, self-administration assays would allow one to determine if PNR-4-20 produced reinforcing effects that are typically predictive of abuse liability in humans. Some studies have shown that high-efficacy agonists such as JWH-018, but not low-efficacy agonists such as $\Delta^{9}$-THC, produce positive reinforcing effects in animal subjects (De Luca et al., 2015). Whether a biased $\mathrm{CB}_{1} \mathrm{R}$ agonist such as PNR-4-20 would exhibit reduced reinforcing effects should be investigated. Understanding the effects of PNR-4-20 on operant behavior, including assays such as drug discrimination and self-administration, could reveal how ligands with novel molecular signaling properties may induce unique behavioral effects.

Overall, the present studies suggest that the IQD analog PNR-4-20 elicits unique effects when administered repeatedly to National Institutes of Health Swiss mice. These effects clearly differentiate PNR-4-20 from traditional, unbiased cannabinoid agonists such as $\Delta^{9}$-THC and JWH-018. Importantly, 
results from these studies reveal that PNR-4-20 elicits significantly less tolerance to hypothermic and cataleptic effects, as well as less persistent antinociceptive tolerance following chronic administration, than nonbiased cannabinoid 1 agonists. This is consistent with its proposed biased signaling through $\mathrm{G}$ proteins relative to $\beta$-arrestins. Future drug development efforts with the IQD scaffold may identify additional cannabinoids biased toward beneficial $G$ protein signaling over $\beta$-arrestin 2 recruitment; these efforts could, perhaps, result in novel therapeutics for difficult disease states.

\section{Acknowledgments}

We thank the University of Arkansas for Medical Sciences Division of Laboratory Animal Medicine for expert husbandry services and Thomas Prisinzano at the Department of Medicinal Chemistry, School of Pharmacy, University of Kansas (Lawrence, KS), for providing rimonabant as a generous gift.

\section{Authorship Contributions}

Participated in research design: Ford, Cabanlong, Tai, Franks, Fantegrossi, Prather.

Conducted experiments: Ford, Cabanlong, Tai, Franks, Fantegrossi.

Contributed new reagents or analytic tools: Penthala, Crooks.

Performed data analysis: Ford, Fantegrossi, Prather.

Wrote or contributed to the writing of the manuscript: Ford, Fantegrossi, Prather.

\section{References}

Berlach DM, Shir Y, and Ware MA (2006) Experience with the synthetic cannabinoid nabilone in chronic noncancer pain. Pain Med 7:25-29.

Brents LK, Gallus-Zawada A, Radominska-Pandya A, Vasiljevik T, Prisinzano TE, Fantegrossi WE, Moran JH, and Prather PL (2012) Monohydroxylated metabolites of the K2 synthetic cannabinoid JWH-073 retain intermediate to high cannabinoid 1 receptor (CB1R) affinity and exhibit neutral antagonist to partial agonist activity. Biochem Pharmacol 83:952-961.

Brents LK, Reichard EE, Zimmerman SM, Moran JH, Fantegrossi WE, and Prather PL (2011) Phase I hydroxylated metabolites of the K2 synthetic cannabinoid JWH-018 retain in vitro and in vivo cannabinoid 1 receptor affinity and activity. PLoS One 6:e21917.

Brust TF, Morgenweck J, Kim SA, Rose JH, Locke JL, Schmid CL, Zhou L, Stahl EL, Cameron MD, Scarry SM, et al. (2016) Biased agonists of the kappa opioid receptor suppress pain and itch without causing sedation or dysphoria. Sci Signal 9:ra117.

Cooper ZD, Comer SD, and Haney M (2013) Comparison of the analgesic effects of dronabinol and smoked marijuana in daily marijuana smokers. Neuropsychopharmacology 38:1984-1992.

Cressey D (2015) The cannabis experiment. Nature 524:280-283.

Cross SA (1994) Pathophysiology of pain. Mayo Clin Proc 69:375-383.

De Luca MA, Bimpisidis Z, Melis M, Marti M, Caboni P, Valentini V, Margiani G, Pintori N, Polis I, Marsicano G, et al. (2015) Stimulation of in vivo dopamine transmission and intravenous self-administration in rats and mice by JWH-018, a Spice cannabinoid. Neuropharmacology 99:705-714.

Devinsky O, Cross JH, Laux L, Marsh E, Miller I, Nabbout R, Scheffer IE, Thiele EA, and Wright S; Cannabidiol in Dravet Syndrome Study Group (2017) Trial of cannabidiol for drug-resistant seizures in the Dravet syndrome. N Engl J Med 376:2011-2020.

Eisenstein M (2015) Medical marijuana: showdown at the cannabis corral. Nature 525:S15-S17.

Fan F, Compton DR, Ward S, Melvin L, and Martin BR (1994) Development of crosstolerance between delta-9-tetrahydrocannabinol, CP 55,940 and WIN 55,212. J Pharmacol Exp Ther 271:1383-1390.

Fonseca CG, Pires W, Lima MR, Guimarães JB, Lima NR, and Wanner SP (2014) Hypothalamic temperature of rats subjected to treadmill running in a cold environment. PLoS One 9:e111501.

Ford BM, Franks LN, Tai S, Fantegrossi WE, Stahl EL, Berquist MD, Cabanlong CV, Wilson CD, Penthala NR, Crooks PA, et al. (2017) Characterization of structurally novel G protein biased $\mathrm{CB}_{1}$ agonists: implications for drug development. Phar macol Res 125:161-177.

Franks LN, Ford BM, Madadi NR, Penthala NR, Crooks PA, and Prather PL (2014) Characterization of the intrinsic activity for a novel class of cannabinoid receptor ligands: indole quinuclidine analogs. Eur J Pharmacol 737:140-148.
Gannon BM, Williamson A, Suzuki M, Rice KC, and Fantegrossi WE (2016) Stereoselective effects of abused "bath salt" constituent 3,4-methylenedioxypyrovalerone in mice: drug discrimination, locomotor activity, and thermoregulation. J Pharmacol Exp Ther 356:615-623.

Guzmán M (2003) Cannabinoids: potential anticancer agents. Nat Rev Cancer 3: $745-755$.

Horswill JG, Bali U, Shaaban S, Keily JF, Jeevaratnam P, Babbs AJ, Reynet C, and Wong Kai In P (2007) PSNCBAM-1, a novel allosteric antagonist at cannabinoid $\mathrm{CB}_{1}$ receptors with hypophagic effects in rats. $\mathrm{Br}$ J Pharmacol 152:805-814.

Howlett AC, Barth F, Bonner TI, Cabral G, Casellas P, Devane WA, Felder CC, Herkenham M, Mackie K, Martin BR, et al. (2002) International Union of Pharmacology. XXVII. Classification of cannabinoid receptors. Pharmacol Rev 54:161-202.

Lynch ME and Ware MA (2015) Cannabinoids for the treatment of chronic noncancer pain: an updated systematic review of randomized controlled trials. $J$ Neuroimmune Pharmacol 10:293-301.

Madadi NR, Penthala NR, Brents LK, Ford BM, Prather PL, and Crooks PA (2013) Evaluation of (Z)-2-((1-benzyl-1H-indol-3-yl)methylene)-quinuclidin-3-one analogues as novel, high affinity ligands for CB1 and CB2 cannabinoid receptors. Bioorg Med Chem Lett 23:2019-2021.

Maida V and Daeninck PJ (2016) A user's guide to cannabinoid therapies in oncology. Curr Oncol 23:398-406.

Martin WJ, Hohmann AG, and Walker JM (1996) Suppression of noxious stimulusevoked activity in the ventral posterolateral nucleus of the thalamus by a cannabinoid agonist: correlation between electrophysiological and antinociceptive effects. $J$ Neurosci 16:6601-6611.

Matsuda LA, Lolait SJ, Brownstein MJ, Young AC, and Bonner TI (1990) Structure of a cannabinoid receptor and functional expression of the cloned cDNA. Nature 346:561-564.

Muramatsu RS, Silva N, and Ahmed I (2013) Suspected dronabinol withdrawal in an elderly cannabis-naive medically ill patient. Am J Psychiatry 170:804.

Nguyen PT, Schmid CL, Raehal KM, Selley DE, Bohn LM, and Sim-Selley LJ (2012) $\beta$-Arrestin2 regulates cannabinoid $\mathrm{CB}_{1}$ receptor signaling and adaptation in a central nervous system region-dependent manner. Biol Psychiatry 71:714-724.

Pergolizzi JV Jr, Taylor R, LeQuang JA, Zampogna G, and Raffa RB (2017) Concise review of the management of iatrogenic emesis using cannabinoids: emphasis on nabilone for chemotherapy-induced nausea and vomiting. Cancer Chemother Pharmacol 79:467-477.

Pertwee RG (1997) Pharmacology of cannabinoid $\mathrm{CB}_{1}$ and $\mathrm{CB}_{2}$ receptors. Pharmacol Ther 74:129-180.

Pertwee RG (2006) The pharmacology of cannabinoid receptors and their ligands: an overview. Int $J$ Obes 30 (Suppl 1):S13-S18.

Piscitelli F, Ligresti A, La Regina G, Coluccia A, Morera L, Allarà M, Novellino E, Di Marzo V, and Silvestri R (2012) Indole-2-carboxamides as allosteric modulators of the cannabinoid $\mathrm{CB}_{1}$ receptor. J Med Chem 55:5627-5631.

Price MR, Baillie GL, Thomas A, Stevenson LA, Easson M, Goodwin R, McLean A, McIntosh L, Goodwin G, Walker G, et al. (2005) Allosteric modulation of the cannabinoid $\mathrm{CB}_{1}$ receptor. Mol Pharmacol 68:1484-1495.

Raehal KM and Bohn LM (2014) $\beta$-Arrestins: regulatory role and therapeutic potential in opioid and cannabinoid receptor-mediated analgesia. Handb Exp Pharmacol 219:427-443.

Reuter SE and Martin JH (2016) Pharmacokinetics of cannabis in cancer cachexiaanorexia syndrome. Clin Pharmacokinet 55:807-812.

Rosenberg EC, Patra PH, and Whalley BJ (2017) Therapeutic effects of cannabinoids in animal models of seizures, epilepsy, epileptogenesis, and epilepsy-related neuroprotection. Epilepsy Behav 70:319-327.

Soergel DG, Subach RA, Burnham N, Lark MW, James IE, Sadler BM, Skobieranda F, Violin JD, and Webster LR (2014) Biased agonism of the $\mu$-opioid receptor by TRV130 increases analgesia and reduces on-target adverse effects versus morphine: a randomized, doubleblind, placebo-controlled, crossover study in healthy volunteers. Pain 155:1829-1835.

Tai S, Hyatt WS, Gu C, Franks LN, Vasiljevik T, Brents LK, Prather PL, and Fantegrossi WE (2015) Repeated administration of phytocannabinoid $\Delta^{9}$-THC or synthetic cannabinoids JWH-018 and JWH-073 induces tolerance to hypothermia but not locomotor suppression in mice, and reduces CB1 receptor expression and function in a brain region-specific manner. Pharmacol Res 102:22-32.

Verty AN, Evetts MJ, Crouch GJ, McGregor IS, Stefanidis A, and Oldfield BJ (2011) The cannabinoid receptor agonist THC attenuates weight loss in a rodent model of activity-based anorexia. Neuropsychopharmacology 36:1349-1358.

Volkow ND, Baler RD, Compton WM, and Weiss SR (2014) Adverse health effects of marijuana use. $N$ Engl J Med 370:2219-2227.

Ware MA, Daeninck P, and Maida V (2008) A review of nabilone in the treatment of chemotherapy-induced nausea and vomiting. Ther Clin Risk Manag 4:99-107.

Weinstein AM and Gorelick DA (2011) Pharmacological treatment of cannabis dependence. Curr Pharm Des 17:1351-1358.

Wiley JL, Lefever TW, Cortes RA, and Marusich JA (2014) Cross-substitution of $\Delta^{9}$-tetrahydrocannabinol and JWH-018 in drug discrimination in rats. Pharmacol Biochem Behav 124:123-128.

Address correspondence to: William E. Fantegrossi, Department of Pharmacology and Toxicology, College of Medicine, University of Arkansas for Medical Sciences, 4301 West Markham Street, Little Rock, AR 72205. E-mail: wefantegrossi@uams.edu 